\title{
Minerv@s Digitais: encorajando e acolhendo mulheres na computação
}

\author{
Larissa M. da F. Galeno, Maria Eduarda H. Lucena, \\ Tainá da S. Lima, Maria Luiza M. Campos
}

Departamento de Ciência da Computação

Universidade Federal do Rio de Janeiro (UFRJ) - Rio de Janeiro, RJ - Brasil

$\{$ galeno, dudahl\}@dcc.ufrj.br,

tainaslima19@gmail.com, mluiza@ppgi.ufrj.br

Abstract. Computing, as known nowadays, was also built by women: Ada Lovelace, Dorothy Vaughan and Margaret Hamilton - these are just a few names that left their mark on history. However, what is currently seen is the withdrawal of professional women from the field. This work aims to present Minerv@s Digitais, an extension project at Federal University of Rio de Janeiro, composed of students from scientific and technological backgrounds, whose main purpose is to reduce the gap between women and men's presence in Computer Science. In the last two years, the project has had many initiatives, such as the hackathon Minerv@ Jam and the event Jornad@s. For 2020, considering the experience that the members already gained, the group plans to reach even larger audiences.

Resumo. A computação, da forma que se conhece hoje, foi desenvolvida também por mulheres: Ada Lovelace, Dorothy Vaughan e Margaret Hamilton são somente alguns dos nomes que ficaram marcados na história. Contudo, o que é visto atualmente é o afastamento de profissionais do sexo feminino da área. Dessa forma, este trabalho tem como objetivo apresentar o Minerv@s Digitais, um projeto de extensão na Universidade Federal do Rio de Janeiro, composto por alunos de cursos científicos-tecnológicos, cujo propósito é diminuir esse afastamento, especialmente na área da computação. O projeto atuou com iniciativas nos últimos dois anos, como a hackathon Minerv@Jam e o evento Jornad@s. Já para 2020, com a experiência que os alunos obtiveram, o grupo tem planos de alcançar públicos ainda maiores.

\section{Introdução}

Em 1842, Ada Lovelace apresentou ao mundo o primeiro algoritmo nas suas notas em meio à tradução da publicação de Luigi Menabrea: "Sketch of the Analytical Engine Invented by Charles Babbage" [CREPALDI et al., 2017]. Com isso, é tida como a primeira programadora, sendo uma fonte de inspiração para as mulheres que viriam a seguir seus passos, como Dorothy Vaughan, a primeira mulher negra a ser promovida a chefe de departamento da NACA (antecessora da NASA). Dorothy ficou famosa pelo seu vasto conhecimento em FORTRAN e pela participação no teste do Projeto Scout [NASA, 2017]. Também pode-se citar Margaret Hamilton, famosa pelo desenvolvimento do programa que possibilitou que o homem chegasse à Lua com o 
Apollo 11, enquanto era diretora chefe da Divisão de Software no Laboratório de Instrumentação do MIT [MIT, 2016].

Apesar da história da computação ser repleta de figuras femininas importantes para o avanço da mesma, este cenário não é mais reproduzido nos dias atuais. No Brasil, por exemplo, apenas 17\% dos programadores são mulheres [FRABASILE, 2018] e, no mundo, $41 \%$ das mulheres que atuam na área de tecnologia desistem de suas carreiras [HEWLETT et al., 2008]. Tais números são consequência da mesma falta de mulheres nos cursos tecnológicos, ainda tidos como "carreiras masculinas".

Sendo assim, o presente trabalho tem como objetivo apresentar o Minerv@s Digitais (lê-se "Minervas Digitais"), projeto de extensão da UFRJ que tem como foco entender a disparidade de gênero na procura pelo curso, a razão do decréscimo ao longo do tempo e a evasão. O projeto trabalha ativamente para a inserção e retenção de mulheres na área da ciência e tecnologia, com ênfase em computação.

Organizado em cinco seções principais, este artigo apresenta na próxima seção uma revisão de literatura e de trabalhos similares, discutindo diferenças no escopo de atuação. Nas seguintes, descreve a organização do grupo e sua característica interdisciplinar, apresentando os tipos de ações desenvolvidas visando contribuir para uma mudança no ecossistema universitário em relação às questões mencionadas. Por fim, serão discutidas as dificuldades e planos futuros do projeto tendo em vista o momento atual de pandemia.

\section{Revisão de literatura e projetos correlatos}

\subsection{Revisão de literatura}

A primeira turma de Ciência de Computação da Universidade de São Paulo (USP) tinha $70 \%$ de mulheres do total de alunos, de acordo com uma publicação do Jornal da USP [SANTOS, 2018]. Entretanto a mesma matéria faz um contraponto com a porcentagem de alunas em 2016, que foi de $15 \%$, refletindo um cenário recorrente atualmente: a escassez de mulheres nos cursos de computação.

A realidade da Universidade Federal do Rio de Janeiro (UFRJ), que não só é considerada uma das melhores do país em largo espectro como também em Bacharelado em Ciência da Computação [FOLHA DE SÃO PAULO, 2019], não difere deste entendimento geral. Não há informações exatas quanto à entrada e à evasão de mulheres dentro do curso, mas baseando-se em dados desde 2010 nota-se que a taxa média de mulheres que ingressam no curso é de aproximadamente $10 \%$. Este cenário, explícito para o corpo docente, é vivido intensamente pelas recém ingressantes.

Evidentemente, tal como uma reação em cadeia, esta situação dentro da academia provoca uma carência de mulheres no mercado de trabalho tecnológico. Ademais, a típica diferença salarial entre os gêneros diante do mesmo cargo, que ocorre na maioria das áreas do conhecimento, não foge à regra na computação. De acordo com Castro [2013], ainda que as mulheres se concentrem na função de analista de sistemas (aproximadamente $49 \%$ dos profissionais), estas - além de receberem, em média, menos que os homens nessa área - podem alcançar um teto salarial de $\mathrm{R} \$ 10.000,00$, enquanto homens atingem os R\$19.000,00. 
Um dos maiores desafios da área de tecnologia é conseguir entender a justificativa para este panorama. Algumas das teorias para o baixo ingresso de meninas nestes cursos de ensino superior dizem respeito ao desinteresse generalizado - gerado por uma falta de incentivo e desconhecimento das áreas de atuação que o curso de Ciência da Computação oferece - e ao surgimento de computadores pessoais associado às estratégias de publicidade e propaganda das empresas para vendê-los - que eram, em sua maioria, direcionadas para homens. Já para evasão, uma pesquisa da Universidade Federal Rural de Pernambuco aponta que a alta reprovação nas disciplinas iniciais atrapalha a retenção de meninas nos cursos computacionais, e é debatida a falta de incentivo e toxicidade que o ambiente das salas de aulas podem ter, gerando a saída das mulheres [SALES et al., 2015].

\subsection{Projetos correlatos}

Marques et. al [2019] apresentam o Meninas Digitais do Vale, um projeto de extensão criado a partir de uma pesquisa feita para discutir e eleger as melhores medidas a serem tomadas para maior adesão feminina aos cursos de Ciência da Computação e Engenharia de Software em um campus da Universidade Federal do Ceará (UFC). A pesquisa foi realizada com base nos artigos publicados nos anais do Women in Information Technology (WIT) de 2016 e 2017, levantando quais ações foram realizadas e classificando-as em categorias, como público alvo, objetivo, etc. Também foi realizado um survey para delinear os perfis das alunas dos cursos citados que, unido à fase de levantamento, levou a um conjunto de ideias a serem desenvolvidas pelo projeto. A partir disso, o Meninas Digitais do Vale promoveu uma série de eventos no ano de 2018, como a realização de palestras a respeito de mulheres que participaram da história da computação, o uso de jogos educacionais para o ensino de computação e oficinas de design thinking para a criação de sistemas.

Outro trabalho semelhante é o Meninas Digitais no Cerrado, cujo desempenho vem desconstruindo conceitos preconceituosos por meio de debates críticos dentro do Instituto Federal de Educação, Ciência e Tecnologia Goiano (IF GOIANO). A iniciativa tem como membros não somente professores de informática e alunos de graduação como ainda estudantes de nível médio e discentes de outras áreas do conhecimento, tornando-a uma frente interdisciplinar. Um total de 40 atividades foram realizadas nos últimos 4 anos, como a promoção do Ada Lovelace Day nos anos de 2017 e 2018, com rodas de conversa e "mini-palestras" sobre a participação feminina no campo científico-tecnológico e as relações entre gêneros [LOUZADA et al, 2019].

Souza et. al [2017] citam em seu artigo publicado na $11^{\circ}$ edição do WIT um relato de experiência do programa Tech Ladies, uma rede que se propõe a ser um local para troca de informação e conhecimento entre mulheres, além de oferecer capacitações tanto técnicas quanto humanas para que estas possam se desenvolver na área de exatas. O projeto conta com uma equipe formada por professoras, empresárias e outras mulheres das mais diversas áreas, como marketing, psicologia, etc. O projeto obteve respostas positivas dos participantes através de algumas iniciativas, como o ArduLadies, em que foi apresentado uma introdução à eletrônica com Arduino, e outras palestras do mesmo tema em eventos sediados por outros programas. Uma oficina sobre empoderamento feminino também foi promovida pela rede em parceria com outras empresas, cujo propósito era inspirar as integrantes por meio de técnicas de Coaching. 
Lauschner et. al [2016] mencionam a atuação do programa Cunhantã Digital, iniciativa originária no Instituto de Computação da Universidade Federal do Amazonas (UFAM) com objetivo de incentivar a participação feminina da região amazônica nas áreas de ciência e tecnologia. Uma grande ação promovida pelo projeto foi o Workshop Cunhantã Digital, que na sua primeira edição se tornou uma ponte entre mulheres profissionais já inseridas no mercado científico-tecnológico e aquelas ainda em formação nessas áreas, além de permitir que mais mulheres tivessem contato com o ramo, estimulando interesse pelo mesmo. Foram realizadas palestras, dinâmicas, debates e outras ações envolvendo mulheres e tecnologia.

Esses projetos, dentre outros associados à rede Meninas Digitais da SBC [SOCIEDADE BRASILEIRA DE COMPUTAÇÃO, 2020], são exemplos de iniciativas que obtiveram bons retornos no âmbito de ações realizadas em seus anos de vigência, assemelhando-se bastante às que o Minerv@s Digitais tem feito nos últimos anos principalmente àquelas que possibilitam que mulheres dentro e fora da universidade tenham maior familiaridade com a área de computação, instigando curiosidade quanto ao tema. Outrossim, o grupo tem trabalhado no sentido de atingir não só alunas de ensino médio e superior como também as de fundamental, em uma tentativa de estimular precocemente o interesse das meninas em ciência e tecnologia. Como será melhor descrito em seções seguintes, o Minerv@s se propõe a não somente capacitar tecnicamente como a oferecer atividades e oportunidades que desenvolvam habilidades humanas e discutam temas relacionados à saúde mental.

\section{O projeto Minerv@s Digitais}

Em suma, o projeto busca entender, reunir e reforçar a presença feminina na tecnologia. Uma de suas premissas básicas é que, se individualmente não conseguiam valorizar sua importância, juntas conseguiriam apoiar e colaborar umas com as outras. Isso inclui alavancar discussões de gênero que, por vezes, são negligenciadas em um ambiente dominado por indivíduos alheios às questões que perpassam a vivência acadêmica feminina.

Guiada por esses questionamentos e pela situação preocupante de poucas mulheres ingressando no curso, a discussão foi levada para uma disciplina obrigatória do quinto período do curso de Bacharelado em Ciência da Computação na UFRJ, que tem como objetivo apresentar aos alunos as possibilidades de atuação na carreira de computação e o impacto que a profissão pode fazer, além de propor debates sobre a área em geral. Esta experiência na disciplina demonstrou necessária a existência de uma iniciativa cujo foco fosse entender a situação do curso no quesito gênero, originando-se, assim, o Minerv@s Digitais. A criação do projeto seguiu como trabalho avaliativo da própria disciplina e, ao fim daquele semestre, fora registrado, organizado e, finalmente, estava pronto para ir a público como um projeto de extensão.

Desde então, promove eventos e as mais diversas atividades - como workshops e hackathons ${ }^{l}$, além da oportunidade de desenvolver pesquisas relativas à temática feminina e apresentá-las à comunidade. Para que tais compromissos possam ser

\footnotetext{
${ }^{1}$ Hackathons são maratonas de programação que separam os participantes em grupos e estes possuem um período de tempo para elaborar uma solução para um dado desafio.
} 
assumidos e efetivados, conta com um conjunto de membros diversificado. Não há restrições quanto à participação masculina ou de qualquer outro gênero, mas entende-se a importância do protagonismo feminino em suas lutas e, portanto, procura-se propagar o equilíbrio e a colaboração dos que compactuam e reforçam tais reivindicações.

Além disso, o grupo acredita que é papel de qualquer movimento social fazer o recorte de classe e combater todas as formas de opressão. A questão não é promover falsa simetria, nem achar que o feminismo deve focar apenas em questões de gênero. Isso é reducionista - e mentiroso. Por isso, a representatividade nas ações do grupo, bem como em sua estrutura interna, é fundamental, estando os membros sempre abertos e receptivos a qualquer um que queira contribuir e participar do projeto, seja como for.

Como forma de concretizar a atuação plural, o projeto se estruturou em setores sem deixar de lado a intersecção entre eles. Assim, pôde-se garantir o desenvolvimento de competências que vão além da computação e organizar de maneira efetiva e pontual a ação de cada aluno, uma vez que cada participante ainda tem suas obrigações acadêmicas a cumprir. Com isso em mente, buscou-se uma organização em torno de 4 eixos, a saber:

- Pesquisa: responsável por coletar, discutir e analisar estatísticas e conteúdos de pesquisas e levantamentos que contribuam para um melhor entendimento das questões centrais ao projeto e para o planejamento de suas ações;

- Comunicação: responsável pelo gerenciamento das redes sociais e produção de conteúdo visual para as mesmas, divulgando oportunidades, trabalhos, premiações e feitos relevantes que tenham mulheres na linha de frente ou como grandes propulsoras, garantindo que não passem despercebidas e alcancem um público maior;

- Público: responsável por planejar e promover ações presenciais e virtuais para atuação e participação do grupo;

- Interno: responsável por intermediar e desburocratizar questões entre o projeto e a Universidade, além de outros órgãos e entidades, como empresas parceiras.

O grupo ainda conta com um pequeno número de membros, consequência direta da baixa entrada de meninas nos principais cursos contemplados pelo projeto, além do fato de que os alunos aos quais o projeto tem mais acesso - os que cursam Bacharelado em Ciência da Computação - não costumam manifestar grande interesse em participar de extensões de cunho mais social. Em virtude disso, o grupo mantém as portas abertas para qualquer estudante que deseja participar voluntariamente do Minerv@s, com a única restrição de que este seja aluno da UFRJ.

Visto isso, é de se esperar que o projeto tenha boa recepção por grande parte do corpo acadêmico, até por aqueles que ainda não percebem claramente a magnitude das discussões levantadas, mas que respeitam e apreciam a importância de uma iniciativa como essa para as atuais e potenciais alunas. Se deparar com mulheres e suas tantas histórias e trajetórias de sucesso inspira outras meninas e mulheres - que aspiram 
anseios brilhantes na ciência e tecnologia - a não só vislumbrar, mas persistir por ocupar este universo também.

\section{Projetos realizados}

Dada a motivação para sua criação e seus principais objetivos, o grupo concluiu que existem várias possíveis maneiras de suas metas serem alcançadas, seja com iniciativas ora presenciais, ora virtuais, em larga ou pequena escala. Por exemplo, a realização de eventos com temas sobre tecnologia ou áreas correlatas direcionados a mulheres, além da participação do projeto em eventos de outras naturezas, levantando discussões e questionamentos acerca da atual conjuntura feminina dentro do mundo tecnológico.

A seguir, os eventos nos quais o Minerv@s Digitais esteve presente como projeto, além de seus próprios eventos, serão apresentados. Discutir-se-á o que são esses projetos, quais os seus objetivos, como e onde ocorreram, as dificuldades e aprendizados obtidos e, sobretudo, qual o papel da extensão dentro deles.

\subsection{Semana Nacional de Ciência e Tecnologia (SNCT)}

De acordo com o próprio site oficial do evento, a Semana Nacional de Ciência e Tecnologia (SNCT) é uma iniciativa apoiada pelo Governo Federal e coordenada pelo Ministério da Ciência, Tecnologia, Inovações e Comunicações (MCTIC), cujo propósito é fomentar o interesse da população, especialmente da parcela jovem, em assuntos e ações relacionados à Ciência, Tecnologia e Inovação. A SNCT é feita anualmente e, durante a semana, as instituições públicas parceiras do evento realizam atividades que giram em torno de um tema central previamente escolhido pela comissão organizadora.

Dentro da Semana, o grupo entrou com papel de guiar o público do evento para uma reflexão e discussão da posição da mulher na sociedade e no campo da ciência em específico. O projeto esteve presente na SNCT nas edições de 2018 e 2019, onde os membros estiveram disponíveis para conversar e mostrar as atividades planejadas, tais como um quebra-cabeça de personagens femininas importantes na computação, um jogo de adivinhação de números por meio do sistema binário e até um jogo virtual desenvolvido por alguns membros do grupo, que consistia em um personagem feminino e outro masculino disputando uma corrida com obstáculos, onde é possível observar e concluir que a mulher possui muito mais barreiras do que o homem para alcançar certos objetivos.

O foco era ofertar práticas direcionadas para crianças e jovens, que estão presentes em maior peso na SNCT, mas qualquer pessoa poderia participar. Sendo assim, uma das dificuldades que a Semana traz é a de conseguir direcionar o discurso para esse público abrangente. No entanto, ao mesmo tempo, isto permite que se pratique a oratória para diferentes idades, além do quesito técnico e criativo no desenvolvimento do jogo e das demais atividades.

\subsection{Visita ao Programa Forças no Esporte (PROFESP) - CPOR/RJ}

O Programa Forças no Esporte, segundo o site oficial ${ }^{2}$, é um projeto desenvolvido pelo Ministério da Defesa com o apoio da Marinha, Exército, Aeronáutica e outros ministérios. Sua principal finalidade é ajudar a melhorar a vida de crianças e

\footnotetext{
${ }^{2}$ http://www.coter.eb.mil.br/index.php/profesp
} 
jovens de baixa renda através de atividades esportivas, culturais e reforços escolares durante seus contraturnos. O programa, presente em todas as unidades federativas do país, é sediado nas dependências militares.

Em 2018, o Minerv@s teve a oportunidade de visitar o projeto sediado no Centro de Preparação de Oficiais da Reserva do Rio de Janeiro (CPOR/RJ), onde a maioria dos contemplados são residentes de comunidades carentes no entorno. Nesta visita foram feitas atividades especialmente em relação à computação desplugada e ao empoderamento feminino de modo mais lúdico, para que as crianças pudessem ter um melhor entendimento. Ademais, foi feita uma roda de conversa sobre carreiras com meninas de ensino médio que participam do PROFESP, procurando instigá-las quanto à área científica e tecnológica e também entender suas perspectivas em relação à mesma.

Com essa visita, o grupo pôde trabalhar como ensinar conceitos de programação de uma forma didática para crianças. Entretanto, ainda assim, algumas das dificuldades encontradas foram a de manter a atenção das crianças e a de criar um ambiente no qual as meninas se sentissem confortáveis em expor suas dúvidas, opiniões e inseguranças. A partir deste comportamento, o grupo conseguiu tirar insumos e presenciar como as meninas se privam, envergonhadas ou com medo, de expor sua resposta, pensamento ou opinião. Assim, foi possível montar outras ações que buscaram trabalhar essas questões.

\subsection{Minerv@Jam}

No dia 7 de dezembro de 2018,o Minerv@s promoveu o evento "Minerv@, Jam" (lê-se "Minerva Jam"), realizado em espaço cedido pelo parceiro Instituto HUB', localizado na própria UFRJ. O evento consistiu em uma hackathon de 8 horas de duração em que os participantes deveriam construir um protótipo de um aplicativo que seguisse o desafio proposto: "Como podemos promover a educação de meninas e mulheres em áreas de vulnerabilidade social utilizando a tecnologia?”.

Durante a Jam, os participantes puderam ter acesso à ferramenta de prototipagem Figma, tendo mentoria sobre ela e uma palestra com um panorama da mulher na engenharia, sendo este último oferecido por um projeto parceiro. Com isso, foram formados times e estes dispuseram das 8 horas para pensar e discutir quais seriam suas ideias de aplicativo, além de projetá-lo utilizando o que foi aprendido previamente.

Ao final do evento, uma banca de jurados decidiu qual seria o protótipo vencedor, e o respectivo time autor foi gratificado com uma capacitação sobre empreendedorismo concedida pela Garagem Get $\mathrm{Up}^{4}$. A ideia premiada foi a de um aplicativo chamado "Ela Manja", que reuniria mentoras disponíveis para que mulheres da periferia pudessem consultá-las para dúvidas, discussões, etc, em assuntos variados.

Os competidores puderam desenvolver habilidades de prototipação, construção de interface focadas no usuário e trabalho em equipe, além do incentivo à pesquisa que o tema gerou nas equipes. Enquanto organizadores, os membros do Minerv@s tiveram a oportunidade de entender a respeito de relacionamentos institucionais com as partes interessadas, já que o evento contou com apoio e patrocínio de empresas. Também foi

\footnotetext{
${ }^{3}$ https://www.parque.ufrj.br/programasespeciais/hub-ufrj/

${ }^{4}$ https://garagemgetup.com/
} 
possível adquirir conhecimentos acerca de gerenciamento de eventos, um domínio que se mostra cada vez mais importante para as ações do projeto. Dito isto, inicialmente, a equipe encontrou problemas em localizar empresas interessadas e acertar no diálogo, todavia, mapeando empresas com objetivos alinhados ao do projeto, foi possível construir um evento produtivo.

\subsection{Jornad@s}

O “Jornad@s" (lê-se "Jornadas") foi um outro projeto oferecido pelo grupo no ano de 2019. O evento consiste de uma tarde de atividades, começando normalmente com algumas palestras e finalizando com um painel de discussões. Apesar de cada edição do Jornad@s ter um tema principal diferente, todos giram em torno de mulheres e suas situações dentro do ramo da tecnologia e ciência. Em 2019 ocorreram as edições "Jornad@s: carreiras", no primeiro semestre, e "Jornad@s: autoconhecimento", no segundo.

A primeira versão, “Jornad@s: carreiras”, teve o objetivo de trazer o participante para uma reflexão e discussão sobre a jornada da mulher em uma área tecnológica, desde a decisão de tomar tal caminho até sua estabilização no mercado de trabalho. Inicialmente foram apresentados alguns dados quanto ao cenário feminino na computação, fazendo um comparativo do passado com o presente. Além disso, também foi realizada uma palestra sobre empreendedorismo e como a mulher se encaixa nisso, oferecida por duas palestrantes da empresa parceira MJV Technology \& Innovation ${ }^{5}$. Por fim, o evento finalizou com o "Painel Jornad@s", onde um corpo de convidadas pôde contar um pouco mais a respeito de como foram suas trajetórias, como mulheres, no mundo da computação. Tal corpo foi formado por alunas e ex-alunas do curso de Bacharelado em Ciência da Computação da UFRJ, bem como professoras do mesmo departamento e convidadas de empresas parceiras.

No segundo semestre de 2019, aconteceu o "Jornad@s: autoconhecimento", onde o objetivo central era debater acerca da saúde mental e como melhorar o autoconhecimento, tanto de maneira genérica quanto sob a ótica de uma mulher inserida no campo da tecnologia. A primeira parte do evento consistiu em uma palestra sobre inteligência emocional ofertada por uma convidada da parceira Eleva Educação ${ }^{6}$, onde foi explicitada sua definição e suas vantagens no tocante ao mercado de trabalho. No painel desta edição houve uma mesa redonda sobre depressão, ansiedade, síndrome do impostor e como tais comportamentos afetam o cotidiano. A mesa foi composta por profissionais e estudantes da psicologia, convidadas da Eleva Educação e uma pesquisadora do projeto de extensão "SuPyGirls"7.

Uma das motivações para a realização desse evento foi o comportamento percebido nas meninas, enquanto crianças, no PROFESP: um comportamento retraído e envergonhado ao expor uma opinião que muitas vezes seria de extrema relevância. Discutindo com alunas de computação da UFRJ, notou-se que é algo que acompanha o crescimento das mulheres até o mercado de trabalho. Assim, por meio do Jornad@s foi possível ter uma troca com o público presente e apresentar a relevância de entender

\footnotetext{
${ }^{5}$ https://www.mjvinnovation.com/pt-br/

${ }^{6}$ https://elevaeducacao.com.br/

Ihttp://meninas.sbc.org.br/portfolio/supygirls/
} 
inteligência emocional e síndrome do impostor para se construir um ambiente de trabalho saudável.

\section{Considerações finais}

O Minerv@s Digitais é um projeto de extensão cujo maior propósito é estimular a curiosidade de meninas e mulheres quanto ao ramo científico e tecnológico, com uma atenção mais direcionada àquelas mais jovens. Nestes dois anos de trabalho, o grupo participou e organizou diversos eventos, a exemplo de sua presença na SNCT, a realização da Jam e os Jornad@s. Embora o Minerv@s seja uma extensão jovem, conseguiu planejar e realizar atividades interessantes que serviram de apoio e fonte de conhecimento para os participantes. Não obstante, justamente por este mesmo motivo, não obteve um grande número de pessoas em seus eventos, a julgar por outros do gênero. $O$ grupo trabalha ativamente para resolver tal obstáculo, mas também acredita que à medida que se torna mais presente, mais é reconhecido.

Desse modo, o grupo dispõe de grandes ideias para esse ano, levando em consideração o atual cenário de pandemia estabelecido. Uma delas é a realização online de uma segunda edição do Minerv@s Jam, com o mesmo foco em prototipagem de aplicativos e sistemas. Além da parte técnica, que os participantes poderão tirar como bagagem do evento e de discussões sobre empoderamento feminino, esta Jam tem como objetivo proporcionar um momento de apoio em meio ao triste cenário de crise sanitária que o país atravessa neste ano de 2020. A estruturação do evento ainda não está completa, mas pretende-se contar com um dia para mentorias, três dias para que os participantes possam elaborar seus projetos e colocá-los em prática e, por fim, um último dia para apresentações dos mesmos.

Acredita-se que o grupo tem enorme potencial transformador, uma vez que atinge cada vez mais mulheres e meninas com a finalidade de incorporá-las e, caso já estejam, mantê-las em carreiras associadas à ciência e tecnologia, prezando sempre por um meio mais isonômico em termos de oportunidades.

\section{Referências}

CREPALDI, C. et al. A História da Computação: Das Máquinas de Calcular aos Computadores Quânticos. , Instituto de Física da Universidade de São Paulo, IF-USP, $92017 . \quad$ jul. Disponível em: http://fap.if.usp.br/ crepaldi/archive/ECF_Final.pdf. Acesso em: 26 abr. 2020.

NASA. Dorothy Vaughan Biography. 2017. Disponível em: https://www.nasa.gov/content/dorothy-vaughan-biography. Acesso em: 27 abr. 2020.

MIT. Scene at MIT: Margaret Hamilton's Apollo code. 2016. Disponível em: http://news.mit.edu/2016/scene-at-mit-margaret-hamilton-apollo-code-0817. Acesso em 27 abr. 2020.

FRABASILE, Daniela. Apenas 17\% dos programadores brasileiros são mulheres. Época Negócios, [S. 1.], 5 fev. 2018. Disponível em: https://epocanegocios.globo.com/Economia/noticia/2018/02/apenas-17-dos-program adores-brasileiros-sao-mulheres.html. Acesso em: 29 abr. 2020. 
HEWLETT, S. A. et al. The Athena Factor: Reversing the Brain Drain in Science, Engineering, and Technology. Harvard Business Review, [S. l.], p. 1-108, 22 maio 2008. Disponível em:

https://store.hbr.org/product/the-athena-factor-reversing-the-brain-drain-in-science-e ngineering-and-technology/10094. Acesso em: 26 abr. 2020.

SANTOS, C. M. Por que as mulheres "desapareceram" dos cursos de computação?. [S. l.]: Jornal da USP, 7 mar. 2018. Disponível em: https://jornal.usp.br/universidade/por-que-as-mulheres-desapareceram-dos-cursos-de -computacao/. Acesso em: 26 abr. 2020.

FOLHA DE SÃO PAULO (SP). Ranking de universidades. [S. l.], 2019. Disponível em: https://ruf.folha.uol.com.br/2019/ranking-de-universidades/principal/. Acesso em: 26 abr. 2020 .

FOLHA DE SÃO PAULO (SP). Ranking de cursos de graduação. [S. l.], 2019. Disponível em: https://ruf.folha.uol.com.br/2019/ranking-de-cursos/computacao/. Acesso em: 26 abr. 2020.

CASTRO, B. Afogados em contratos: o impacto da flexibilização do trabalho nas trajetórias dos profissionais de TI. 2013. Tese (Doutorado em Ciências Sociais) Instituto de Filosofia e Ciências Humanas, Universidade Estadual de Campinas, $[S$. l.], 2013.

SALES, A. et al. Dificuldades para o ingresso e permanência na Ciência e Engenharia da Computação: Um Olhar Feminino. , [S. 1.], 13 fev. 2015. Disponível em: http://www.ufpb.br/evento/index.php/18redor/18redor/paper/view/1936/854. Acesso em: 26 abr. 2020.

MARQUES, A. B. et al. Unindo pesquisa e extensão para fortalecer a participação feminina em cursos de Computação de uma universidade: Projeto Meninas Digitais do Vale. $13^{\circ}$ WIT - Women in Information Technology, [S. 1.], p. 31-40, 12 jul. 2019.

LOUZADA, N. C. et al. Agindo sobre a diferença: atividades de empoderamento feminino em prol da permanência de mulheres em cursos de Tecnologia da Informação. $13^{\circ}$ WIT - Women in Information Technology, [S. 1.], p. 69-78, 12 jul. 2019.

SOUZA, A. C. M. et al. Relato Tech Ladies: redes de colaboração entre mulheres na tecnologia. $11^{\circ}$ WIT - Women in Information Technology, [S. 1.], p. 1181-1185, 6 jul. 2017.

LAUSCHNER, T. et al. Cunhantã Digital: programa de incentivo à participação de mulheres da região amazônica na Computação e áreas afins. $10^{\circ}$ WIT - Women in Information Technology, [S. 1.], p. 20-24, 4 jun. 2016.

SOCIEDADE BRASILEIRA DE COMPUTAÇÃO. Meninas Digitais. Meninas Digitais - Programa Meninas Digitais da Sociedade Brasileira de Computação. [S. l.], 2020. Disponível em: http://meninas.sbc.org.br/. Acesso em: 14 maio 2020.

SEMANA Nacional de Ciência e Tecnologia. Disponível em: https://snct.mctic.gov.br/. Acesso em: 25 abr. 2020. 